\title{
GSK3 Function in the Brain during Development, Neuronal Plasticity, and Neurodegeneration
}

\author{
Pamela Salcedo-Tello, Abril Ortiz-Matamoros, and Clorinda Arias \\ Departamento de Medicina Genómica y Toxicología Ambiental, Instituto de Investigaciones Biomédicas, \\ Universidad Nacional Autónoma de México, AP 70-228, 04510 Ciudad de México, Mexico \\ Correspondence should be addressed to Clorinda Arias, carias@servidor.unam.mx
}

Received 1 February 2011; Accepted 7 March 2011

Academic Editor: Peter Crouch

Copyright ( 2011 Pamela Salcedo-Tello et al. This is an open access article distributed under the Creative Commons Attribution License, which permits unrestricted use, distribution, and reproduction in any medium, provided the original work is properly cited.

GSK3 has diverse functions, including an important role in brain pathology. In this paper, we address the primary functions of GSK3 in development and neuroplasticity, which appear to be interrelated and to mediate age-associated neurological diseases. Specifically, GSK3 plays a pivotal role in controlling neuronal progenitor proliferation and establishment of neuronal polarity during development, and the upstream and downstream signals modulating neuronal GSK3 function affect cytoskeletal reorganization and neuroplasticity throughout the lifespan. Modulation of GSK3 in brain areas subserving cognitive function has become a major focus for treating neuropsychiatric and neurodegenerative diseases. As a crucial node that mediates a variety of neuronal processes, GSK3 is proposed to be a therapeutic target for restoration of synaptic functioning and cognition, particularly in Alzheimer's disease.

\section{GSK3 Signaling Pathway}

Many diseases of the central nervous system are characterized by changes in the structural organization of neuronal networks, developmental abnormalities, or dysregulation of signaling pathways, leading to altered brain plasticity and, ultimately, neurodegeneration. The proline-directed serine/threonine kinase, glycogen synthase kinase 3 (GSK3), has been suspected to be a contributing factor in psychiatric illness and age-associated neurodegenerative diseases for some time [1]. The involvement of GSK3 misregulation in a variety of brain abnormalities strongly supports its pivotal role as a metabolic crossroads for controlling basic mechanisms of neuronal function from brain bioenergetics to establishment of neuronal circuits, modulation of neuronal polarity, migration, neuronal proliferation, and survival [2]. In particular, the role of GSK3 in phosphorylation of cytoskeletal proteins impacts neuronal plasticity, as cytoskeletal constituents are involved in the development and maintenance of neurites, and changes in the rate of stabilization/destabilization of microtubules (MT) could influence major cellular compartments of neurons, such as dendrites, spines, axons, and synapses.

The metabolic function of GSK3 was first described in glycogen metabolism, as GSK3 phosphorylates glycogen synthase in response to insulin [3]. Since then, research has identified a multitude of substrates and functions for this enzyme. GSK3 exists in cells as two distinct gene products, $\alpha$ and $\beta$, which exhibit high homology in the catalytic domain but differ in the N- and C-terminal sequences [4]. GSK3 is ubiquitous throughout the animal kingdom [5] and is widely expressed in all tissues with particularly abundant levels in the brain [4], where the neuron-specific isoform GSK3 $\beta 2$ is found [6].

GSK3 is unique because it is constitutively active, and upstream signals downregulate its activity by phosphorylation at specific residues. The most important phosphoresidues are serine (Ser) 21 for GSK3 $\alpha$ and Ser9 for GSK3 $\beta$, which inhibit its kinase activity $[2,7-10]$, while phosphorylation on tyrosine (Tyr) residues (Tyr 216/279 for GSK $3 \beta$ and GSK3 $\alpha$, resp.), is required for its activation [11-13]. The latter kind of phosphorylation is mediated by 


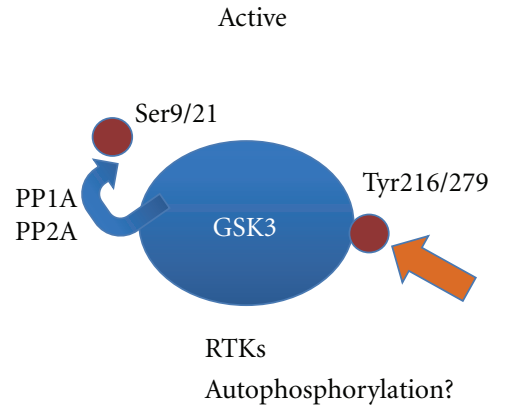

(a)

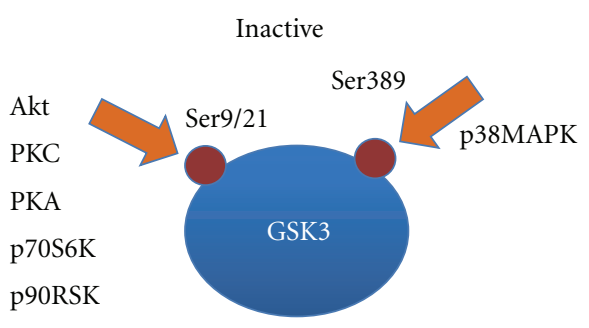

(b)

FIGURE 1: Modulation of GSK3 activity by phosphorylation. Protein phosphatases 1 and 2A activate GSK3 by removing Ser9/21 phosphorylation. It has also been reported that phosphorylation in tyrosine residues by members of the receptor tyrosine kinase family of cell surface receptors (RTKs) or by autophosphorylation may activate GSK3. On the other hand, signaling networks activate several protein kinases, which may bring about phosphorylation of different residues and inhibition of GSK3.

diverse tyrosine kinases [14] or by autophosphorylation [15] (Figure 1).

Multiple kinases can phosphorylate Ser21/9, including Akt, protein kinases A and C, p70S6K, and p90RSK [16]. In contrast, protein phosphatases 1 (PP1) and 2A (PP2A) dephosphorylate the inhibitory site of GSK3, resulting in activation of the enzyme. In addition to the inhibitory phosphorylation of GSK3 $\beta$ described above, an additional inhibitory site at Ser389 has been detected in the brain, which is phosphorylated by p38 mitogen-activated protein kinase (MAPK) [17].

In addition to its phosphorylation state, GSK3 activity may be regulated by proteolysis through disruption of the axin- $\beta$-catenin complex [18] or N-terminal cleavage by the calcium-dependent protease calpain [19]. GSK3 activity also depends on its cellular localization. Although GSK3 is predominantly located in the cytosol, it is also present in nuclei and mitochondria, where it is highly activated compared with the cytosolic pool [20]. Nuclear GSK3 regulates the expression of diverse genes via various transcription factors, such as Ap-1, $\beta$-catenin, c-myc, and p53 [16]. Subtle control of GSK3-mediated activation and inhibition is required to ensure a proper balance among cell morphoregulation, proliferation, and growth. Thus, prolonged inhibition of GSK3 is associated with hypertrophic cell growth [21], while sustained activation is associated with neurodegeneration [22]. Unlike other kinases, the majority of GSK3 substrates require a "priming" phosphorylation on Ser/Thr residues, which is catalyzed by a protein kinase other than GSK3 $[2,10,16]$.

\section{Implications of GSK3 Activity in Brain}

In adulthood, both GSK3 $\alpha$ and GSK3 $\beta$ are expressed in mice adult brain and are particularly enriched in hippocampus, neocortex, and cerebellum [23]. In rodent adult hippocampus GSK3 $\beta$ is more abundant than GSK3 $\alpha$ [24], and in aged hippocampus GSK3 $\beta$ is elevated, but not GSK3 $\alpha$ [25]. Two splice variants of the GSK3 $\beta$ gene are found in neurons from mouse, rat, and human: GSK3 $\beta 1$ and GSK3 $\beta 2$, the latter being highly expressed during brain development and specific to neurons [6,26-28]. The two isoforms are differentially involved in phosphorylation of different substrates [29] and establishment of neuronal polarity and axon guidance [2, 30-32].

The importance of GSK3 in brain function has been established by several studies in transgenic mice, which have shown different neurological defects depending of the specific GSK3 isoform involved. While deletion of GSK3 $\beta$ is lethal, heterozygote mice survive and present increased anxiety and reduced exploration [33-35]. Conversely, knockout GSK3 $\alpha$ mice are quite normal [36], although neuron-specific knockout of GSK3 $\alpha$ results in reduced anxiety, locomotor activity, and aggression [37]. Overexpression of an inhibitory phosphorylation-resistant form of GSK3 results in increased locomotor activity and has been proposed as a model of manic illness [38]. Moreover, overexpressed GSK3 $\beta$ in dentate gyrus results in tau-dependent neurodegeneration of this region [39]. In the brain, GSK3 regulates developmental processes, including neurogenesis, migration, axon growth and guidance, and synaptic plasticity [40], and its activity is controlled through several signaling pathways activated by growth factors, wingless (Wnt) proteins, G-protein-coupled receptors (GPCR), $\beta$-arrestin, among other proteins [41].

Abnormal activation of GSK3 has been associated with several neurological and psychiatric disorders that share developmental abnormalities and altered neurocircuitry maintenance, such as schizophrenia, bipolar disorder, autism, and Alzheimer's disease (AD) [42-46]. GSK3 is indeed a common therapeutic target for neuropsychiatric drugs $[41,47]$.

\section{Signaling Pathways Involved in GSK3 Activity in Brain}

GSK3 is a downstream component of several signaling pathways in the brain. One of the most studied is the phosphoinositide-3-OH kinase (PI3K)/Akt pathway, which plays a crucial role in differentiation and survival of neuronal and glial cells [48]. Growth signals, Ras proteins [49], 
Wnt signaling on Wnt signaling off
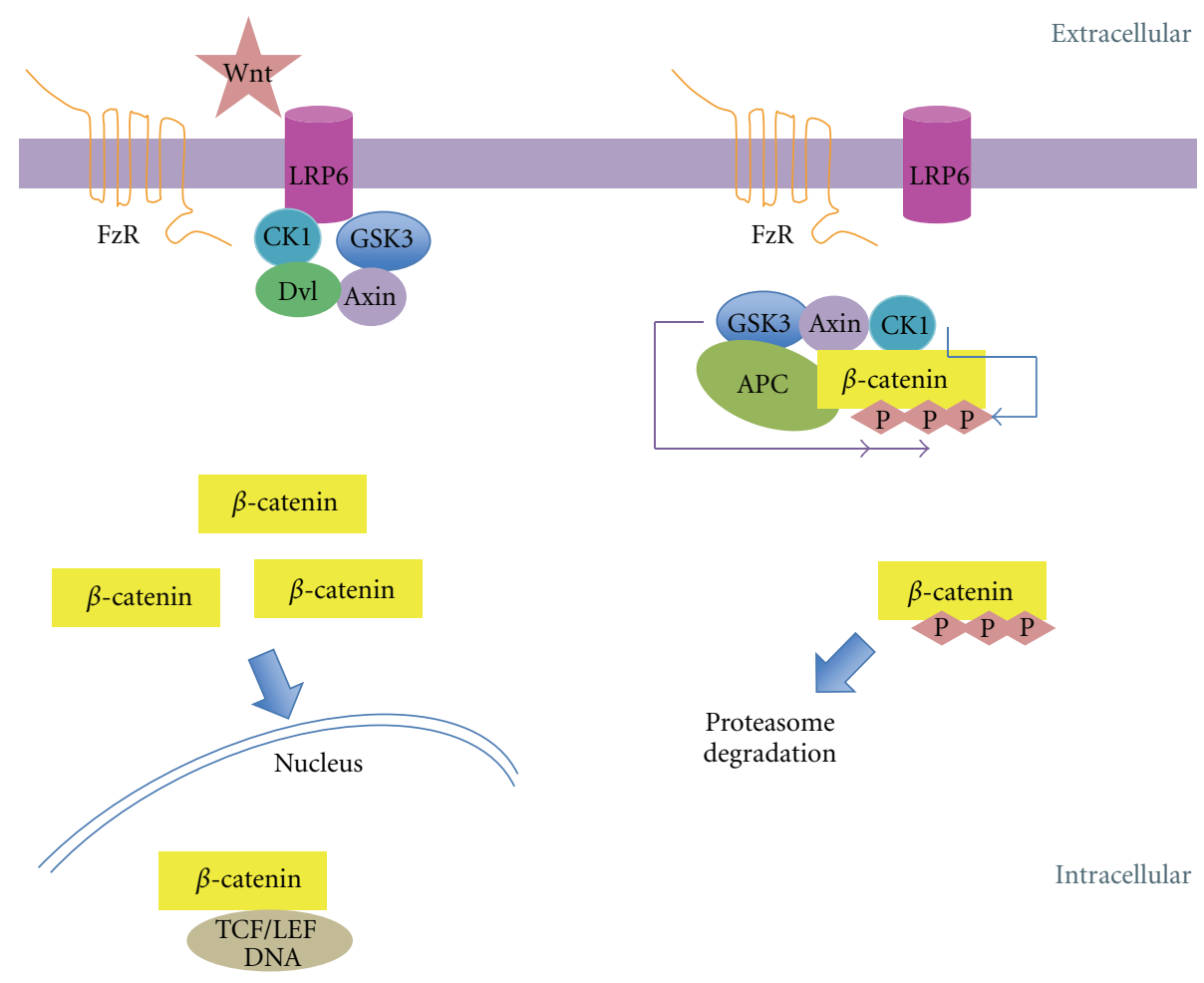

FIgURE 2: Canonical Wnt signaling and GSK3 regulation. Wnt activation through Frizzled receptor (FzR) induces destabilization of the protein complex composed of axin, adenomatous polyposis coli (APC) protein, $\beta$-catenin, casein kinase (Ck1), and GSK3, which results in GSK3 inhibition leading to the induction of $\beta$-catenin/TCF target gene expression. When Wnt signalling is off the GSK3/axin complex is not inhibited and $\beta$-catenin phosphorylated and is degraded by the proteasome machinery.

or diminished phosphatase and tensin homolog (PTEN) all activate the catalytic subunit of PI3K, which phosphorylates phosphatidylinositol-4,5-bisphosphate (PIP2) to phosphatidylinositol-3,4,5-trisphosphate (PIP3) and activates phosphoinositide-dependent protein kinase-1 (PDK1). Meanwhile, signaling proteins with pleckstrin homology $(\mathrm{PH})$ domains accumulate at sites of PI3K activation on the inner surface of the plasma membrane through interactions between their $\mathrm{PH}$ domains and the phospholipid products of PI3K. Next, the serine-threonine kinase Akt/protein kinase B is recruited and phosphorylated by PDK-1, which stimulates the catalytic activity of Akt, in turn phosphorylating GSK3 to downregulate its activity.

The canonical Wnt pathway is also classically involved in negative regulation of GSK3. Although the role of Wnt proteins in mature neurons remains largely unexplored, recent data indicate that Wnts are important mediators of neuronal function, neuronal morphology, neurogenesis, and synaptic plasticity [50-52]. Interestingly, Wnt signaling has also been implicated in neurological disorders associated with developmental abnormalities, such as schizophrenia [53], as well as in chronic neurodegenerative diseases, such as $\mathrm{AD}$ [54]. Extracellular secreted Wnt proteins activate Frizzled receptor and/or the low-density lipoprotein-related protein 5 and 6 (LRP5/6) receptors, leading to the characteristic activation of the Wnt canonical pathway [55].
Due to Frizzled activation, the Dishevelled mammalian homolog Dvll is recruited, inducing destabilization of the protein complex composed of axin, adenomatous polyposis coli (APC) protein, $\beta$-catenin, and GSK $3 \beta$, which results in GSK3 $\beta$ inactivation [56]. Inhibition of GSK3 $\beta$ favors an increase in unphosphorylated $\beta$-catenin levels, allowing interaction with members of the lymphoid enhancer factor/ T-cell factor (LEF/TCF) family of transcription factors and, as a consequence, promoting the expression of cell survival genes [57]. Although the molecular mechanism of GSK3 inhibition is not completely understood, Wnt signaling has recently been reported to trigger the sequestration of GSK3 from the cytosol to multivesicular organelles, preventing its interaction with cytoplasmic substrates [58] (Figure 2).

The outcome is different in the absence of the Wnt stimulation, which may occur due to lack of Wnt ligands or the presence of Wnt negative modulators, such as the extracellular protein Dickkopf-1 (DKK1), which regulates the canonical Wnt signaling, or the secreted Frizzled-related protein, which modulates both canonical and noncanonical Wnt signaling [59]. Under these circumstances, GSK3 $\beta$ is activated and able to phosphorylate its target proteins. Several regulators also target $\beta$-catenin/GSK3 $\beta$ signaling. For example, the product of disrupted in schizophrenia 1 (DISC1) gene inhibits GSK3 $\beta$ activity through a direct physical interaction, causing stabilization of $\beta$-catenins. 
DISC1 loss-of-function in the dentate gyrus has been shown to result in reduced neural progenitor proliferation and to elicit hyperactive and depressive behaviors in mice [60], suggesting the involvement of GSK3 $\beta$ overactivation in mental illnesses, such as depression and schizophrenia. Moreover, DISC1 function seems to be essential for neural progenitor proliferation in embryonic brains and in the dentate gyrus of adult brains through its ability to control GSK3 activity and to maintain $\beta$-catenin levels, which ultimately impacts the neural circuitry [60].

GSK $3 \beta$ is also a downstream mediator of dopamine signaling via the dopamine D2 receptor/ $\beta$-arrestin 2/PP2A complex. In this signaling pathway, Akt activates neuregulin1 signaling leading to inhibition of GSK3 $\beta$ activity [61]. Interestingly, neuregulin-1 has been also implicated as schizophrenia risk factor [62].

In addition to the described role of GSK $3 \beta$ in neurodevelopment, it has been recently found the potentiation of Notch signalling by PI3K through GSK3 $\beta$ inhibition [63]. The Notch pathway has been implicated in controlling cell fate, differentiation, development as well as synaptic plasticity, learning and memory [64].

\section{GSK3: A Switch for Cytoskeletal Reorganization and Synaptic Plasticity}

Changes in neuronal morphology and plasticity are affected by GSK3-induced phosphorylation of proteins involved in the modulation of MT and neurofilament stabilization, which affect the cytoskeleton [65]. Among these proteins are tau, microtubule-associated protein 2 (MAP2), microtubuleassociated protein 1B (MAP1B), collapsin response mediator protein 2, APC, axin, neurofilaments, kinesin light chain, and cytoplasmic linker protein $[9,16,30,31,40,53,66-70]$.

The induction of polarity during neuronal development is essential for the establishment of circuits that support complex functioning $[71,72]$. Subcellular location of the inactive form of GSK3 $\beta$ varies depending on the state of neuronal polarization, as it moves from nonpolarized neurites to the neurite tip that will form the axon at the beginning of the differentiation process. Local inactivation of GSK3 is important to allow axonal growth concurrent with its activation in dendrites [73-76]. These mechanisms support the establishment of neuronal polarity, which is dependent on the stability and dynamism of the MT in each neuronal compartment $[40,53]$. The relationship between GSK $3 \beta$ and the microtubule stabilizing protein complex APC-mPar3, which are both present at the tip of the actively growing nascent axon, is important for the establishment of neuronal polarity. Shi and colleagues [74] have demonstrated that spatially regulated GSK3 activity in hippocampal neurons during development leads to axonal generation [74]. The inactivation of GSK3 at the nascent axon is required for mPar3 targeting through APC and kinesin-mediated transport at the plus end of the axonal MT [74].

Two further studies showed that GSK3 $\beta$ inhibition in hippocampal neurons induces formation of multiple axons $[75,76]$. However, the role of GSK3 in neurodevelopment remains only partially understood due to contradictory data; other studies have found that GSK3 inhibition induces axonal spreading, reduces axonal elongation, and increases growth cone size, but it does not induce the formation of multiple axons [66, 68, 77-79].

One mechanism related to both synaptic reorganization and MT dynamics is Wnt signaling [80-82], which directs the growing axon towards the synaptic terminal. This process involves the reduction of axonal growth speed and the extension of axonal distal portions at the growth cone [83] until arborization forms functional synaptic endings where the presynaptic apparatus can be assembled. Transmembrane proteins, such as neuroligin/neurexin and cadherins, are also involved in this process and serve to regulate assembly on both sides of the synapse [52, 84]. Wnt proteins have a fundamental role in synapse formation, acting as retrograde signals that regulate assembly of the presynaptic apparatus [84]. Specifically, Wnt7a has a dual function in synaptic differentiation, promoting axon remodeling and increasing incorporation of synaptic proteins $[66,84]$. These effects are linked to changes in the reorganization and dynamics (stabilization-destabilization) of MT, which are achieved through the canonical Wnt signaling, independent of the transcription pathway, in which GSK $3 \beta$ activity is inhibited, and, consequently, the phosphorylation state of the axonal MAP1B is reduced [84-86]. The addition of Wnt7a to neuronal cultures reduces MAP1B phosphorylation and induces MT depolymerization from growing areas of the axon, promoting axonal growth cone enlargement and axonal spread $[51,66,87]$. The classical inhibition of GSK3 $\beta$ by lithium chloride $(\mathrm{LiCl})$ reproduces the effects of $\mathrm{Wnt} 7 \mathrm{a}$, inducing axonal arborization and widening and enlargement of the growth cone through remodeling of axonal MT during postnatal development of cerebellar cells [52, 87, 88]. On the other hand, it has been shown that Wnt7a increases the level of Synapsin I (SynI), which is known to be involved in synapse formation, as well as in the maturation and transport of synaptic vesicles in areas of growth $[87,89,90]$. Accumulation of SynI promotes both axonal remodeling and synaptogenesis during cerebellar development [87] and is mimicked by LiCl treatment $[66,88,91]$.

GSK3 is also present in mature synapses [92], where its activity, along with that of cyclin-dependent kinase (Cdk5), participates in the recovery of synaptic vesicles during high neuronal activity. During this process, Cdk5 phosphorylates the GTPase dynamin I, and then GSK3 $\beta$ phosphorylates the same dynamin I [93]. Both phosphorylation events are necessary and sufficient to trigger and maintain activitydependent bulk endocytosis of vesicles [94].

As a result of controlling different morphofunctional aspects of adult brain plasticity, GSK3 also plays a role in long-term potentiation (LTP) $[95,96]$ and long-term depression (LTD). LTP might be considered the electrophysiological correlate of learning based on its synaptic mechanisms and long-lasting experience-dependent cortical circuits [97-99]. On the other hand, LTD has been suggested as a mechanism to enhance the signal-to-noise ratio of sensory input from stored memories [97]. Some studies have shown that GSK $3 \beta$ inhibition upregulates and maintains LTP $[24,50,91,100-102]$, while GSK $3 \beta$ remains active during 
LTD [101]. In rat hippocampus, GSK3 $\beta$ overactivation has been shown to impede LTP and affect synapses by decreasing both synaptic transmission and release of the presynaptic neurotransmitter glutamate [91]. This is regulated by proteins associated with synaptic vesicles, such as SynI [103-108], which is considered to be a synaptic plasticity marker $[109,110]$. GSK3 $\beta$ activation inhibits SynI expression after LTP induction and simultaneously disrupts SynI clustering, which results from elevated neuronal activity [91].

An other evidence that underscores the importance of GSK3 in brain plasticity is derived from experiments conducted in rat hippocampus by Gómez de Barreda and colleagues. The authors found that inhibitory phosphorylation of GSK3 at Ser9 increased at the time of LTP induction was maintained for up to one hour in vivo and was significantly higher in the hippocampal CA1 and dentate gyrus subregions, which are involved in learning and memory acquisition [39]. Transgenic mice overexpressing GSK3 showed reduced LTP induction [100]. These data confirm the significant participation of GSK3 in LTP regulation by enabling LTP when its catalytic activity is inhibited and preventing LTP when it is overactive. The inhibition of the two main signaling pathways (insulin/PI3K and Wnt) which induced an activation of GSK3 also prevents the induction of LTP [50, 64, 111-113].

GSK3 has been shown to induce LTD through presynaptic and postsynaptic mechanisms. In the presynaptic neuron, upregulation of GSK3 decreases the expression of SynI [91], which has been linked to a decrease in glutamate release [103]. In the postsynaptic neuron, GSK3 activation causes changes in levels of synapse-associated proteins [114, 115], evident as downregulation of the NR2A/B subunits of NMDA receptors and of the scaffolding protein postsynaptic density 93 (PSD93) [24, 91]. In addition, a transient activation of NMDA receptors and endocytosis of AMPA receptors occurs $[116,117]$, leading to the loss of GSK3 inhibition due to insufficient $\mathrm{Ca}^{2+}$ entry. This GSK3 inhibition is mediated by NMDA-PI3K-Akt signaling $[112,118]$. Over-activity of GSK3 may also induce MT destabilization in dendrites and axons [80, 86, 119] (Figure 3).

Overexpression of GSK $3 \beta$ in mice prevents the induction of LTP [100] and causes spatial memory deficits [120]. These data suggest that GSK3 $\beta$ plays an essential role in memory formation through three general processes: (i) phosphorylation of substrates involved in synaptic remodeling, necessary for the establishment of new connections, (ii) turnover of cytoskeletal proteins such as MAPs, actin, and tubulin, promoting disassembly, a condition required for a proper synaptic reorganization, and (iii) involvement in the two major forms of synaptic plasticity in the brain, LTP, and LTD [121].

In summary, the functional consequence of GSK3 overactivation in mature neurons is inhibition of LTP and induction of LTD $[101,121]$, which could be linked to deficiencies of memory and learning characteristic of some neurological diseases, such as AD.

\section{GSK3 and Alzheimer's Disease}

$\mathrm{AD}$ represents a serious epidemiological problem, as it is now recognized as the most common age-related neurodegenerative disease. Evidence supports a role for GSK3 in producing some of the characteristic hallmarks of $\mathrm{AD}$ : extracellular accumulation of amyloid- $\beta$ protein $(\mathrm{A} \beta)$ and intraneuronal neurofibrillary tangles (NFTs) composed of hyperphosphorylated forms of tau and inflammatory markers [122]. All of these effects contribute to synaptic and neuronal loss and memory decline $[123,124]$.

It has been proposed that overactivation of GSK3 in AD leads to inhibition of LTP and may partially explain the learning and memory deficits present early in this neurodegenerative disorder. On the other hand, changes in GSK3 activity may be a molecular link between the two main histopathological markers: $\mathrm{A} \beta$ overproduction and tau hyperphosphorylation $[39,46,125,126]$.

The NFTs that accumulate in AD are anomalous filamentous structures composed mainly of abnormal, hyperphosphorylated forms of tau protein [127]. Hence, numerous studies have focused on identification of the protein kinases and phosphatases regulating tau phosphorylation in vivo. GSK $3 \beta$ was recognized as a primary kinase involved in tau phosphorylation, as was apparent from the first studies that termed it tau protein kinase-I [128]. Thus, GSK3 $\beta$ has been identified as one of the major enzymes mediating tau hyperphosphorylation at the residues implicated in neurodegenerative tauopathies, including AD [129].

Normally, tau protein contains a total of 85 phosphorylable sites: 45 Ser, 35 Thr, and 5 Tyr. Of these, 40 have been identified as phosphorylated in insoluble tau in AD brain: 28 Ser, $10 \mathrm{Thr}$, and $2 \mathrm{Tyr}$, and GSK $3 \beta$ can phosphorylate 23 of these sites [130]. Although GSK $3 \beta$ commonly needs priming phosphorylation of tau, three sites were recently found that can be phosphorylated by GSK3 $\beta$ alone, without priming: Ser396, Ser400, and Ser404 [131]. Furthermore, initial phosphorylation of the Ser214 by cAMP-dependent protein kinase was shown to lead to the rapid modification of four additional sites by GSK3 $\beta$ [131]. Studies in transgenic mouse models have shown that overexpression of GSK3 $\beta$ results in neurodegeneration and have unequivocally demonstrated that GSK3 $\beta$ phosphorylates tau in AD-related phosphoepitopes in vivo $[93,132,133]$. Moreover, co-overexpression of tau and GSK $3 \beta$ synergistically increased tau phosphorylation and induced neuronal death in a transgenic model in Drosophila [134] while GSK3 inhibition reduces the phosphorylation and aggregation of tau $[135,136]$. Similarly, tau hyperphosphorylation and neurodegeneration after GSK3 $\beta$ overexpression are exacerbated by co-overexpression of tau with mutations characteristic of frontotemporal dementia with parkinsonism, associated with chromosome 17 (FDTP17). This study also showed that tauopathy progression could be prevented by administration of a GSK $3 \beta$ inhibitor at the first signs of pathology [133]. Tau knockout mice overexpressing GSK3 $\beta$ show reduced hippocampal degeneration, indicating that tau partially contributes to the pathology observed in mouse brain [39]. Finally, GSK3 $\beta$ inhibitors decrease tau phosphorylation and amyloid deposition in 

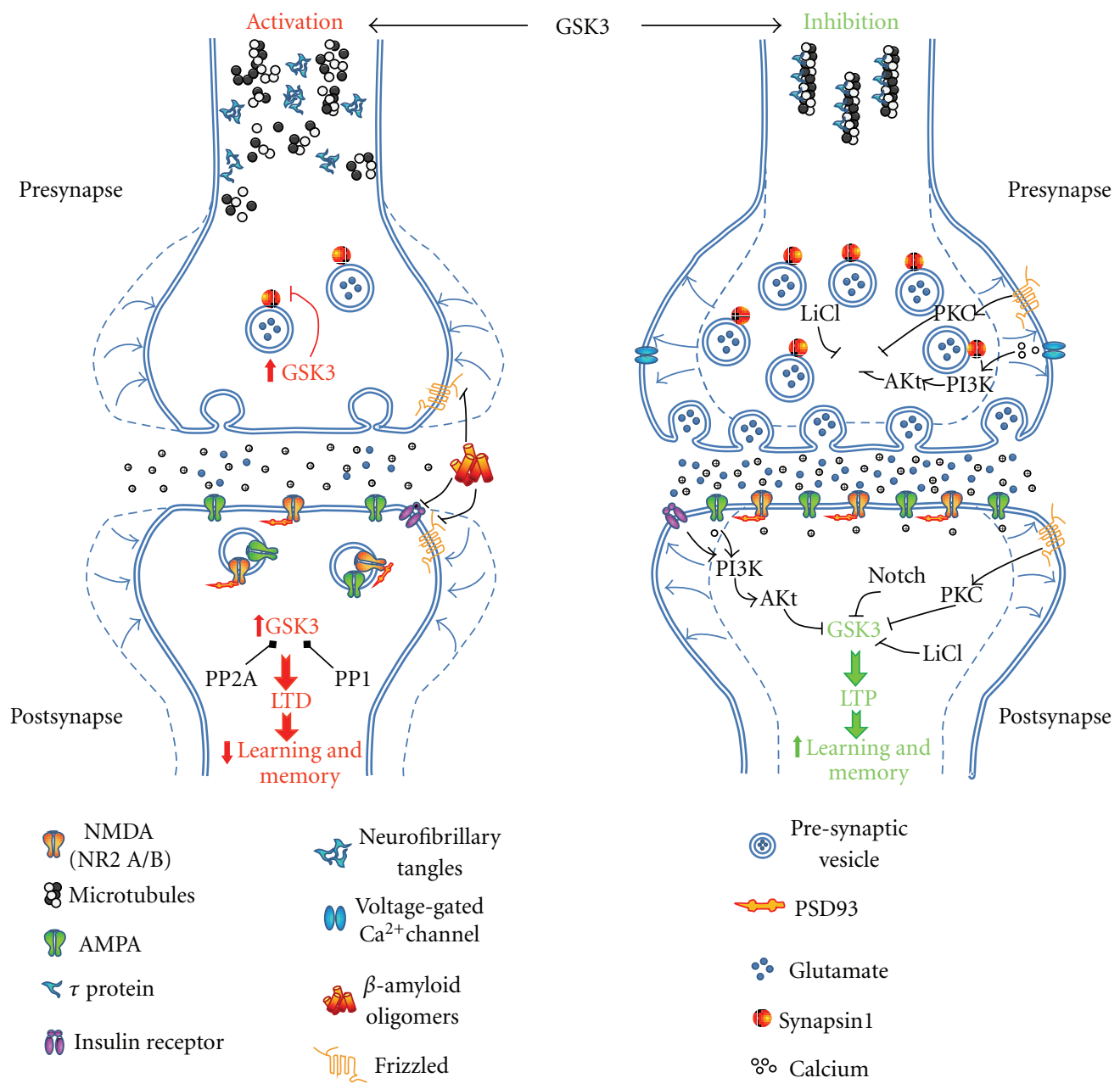

FIGURE 3: Schematic representation of pre- and postsynaptic mechanisms involved in neuronal plasticity and the role of GSK3. In the presynapse GSK3 activity decreases the expression of SynI reducing the release of glutamate while in postsynapses GSK3 transiently activates NMDA receptors leading to endocytosis of AMPA receptors and reduces the levels of PSD93 protein, favoring LTD. In contrast, Wnt and PI3K signaling pathways or pharmacological inhibition of GSK3 by $\mathrm{LiCl}$ supports the induction of LTP, facilitating learning and memory. GSK3 inhibition is also involved in axon and dendritic widening in both pre- and postsynaptic sites. Serine/threonine phosphatases PP1 and PP2A can activate GSK3 regulating phosphor-GSK3 levels through its dephosphorylation. GSK3 is important in the modulation of multiple signaling pathways including Notch pathway that plays an important role in different developmental processes. In AD, amyloid$\beta$ oligomers inhibit Wnt and insulin signaling pathways leading to activation of GSK3. In addition, GSK3 overactivation mediates $\tau$ hyperphosphorylation and microtubule destabilization.

a double transgenic mouse model coexpressing human mutant amyloid precursor protein (APP) and tau [137]. In brains of $\mathrm{AD}$ patients, GSK3 $\beta$ colocalizes with NFT [138], and active GSK3 $\beta$ is present in neuronal cytoplasm of neurons with tangle-like inclusions when abnormal tau hyperphosphorylation begins [139]. In fact, polymorphisms in GSK3 were recently reported to be risk factors for lateonset $\mathrm{AD}[140,141]$.

Evidence suggests that GSK $3 \beta$ regulates APP processing $[126,142]$, leading to increased production of $A \beta$. Neuronal exposure to $A \beta$ increases GSK $3 \beta$ activity through PI3K inhibition [143], causing a positive feedback loop. A $\beta$ peptide can regulate GSK3 activity, acting as an insulin receptor antagonist and preventing activation of PI3K and Akt. In turn, the absence of activated Akt prevents the inhibitory phosphorylation of GSK3, increasing its activity [144]. A $\beta$ seems to interfere with the Wnt canonical pathway as well, leading to increased GSK3 activity [145]. Thus, deregulation of GSK3 in AD might be due, in part, to alterations in insulin and Wnt signaling. In the canonical Wnt signaling pathway, the gene for LRP6 coreceptor has been identified as a risk factor for late-onset AD in ApoE4-negative individuals [146]. Interestingly, it has been suggested that the Wnt pathway might be inhibited by ApoE protein, which likely binds to the coreceptor LRP5/6 [147]. Moreover, the ApoE4, implicated in sporadic AD [148], may activate GSK3 [46, 149].

Wnt dysregulation has also been implicated in AD. For example, protein Dickkopf-1 negatively modulates the canonical Wnt signaling pathway and thus activates GSK3. DKK1 colocalizes with NFT and dystrophic neurites in 


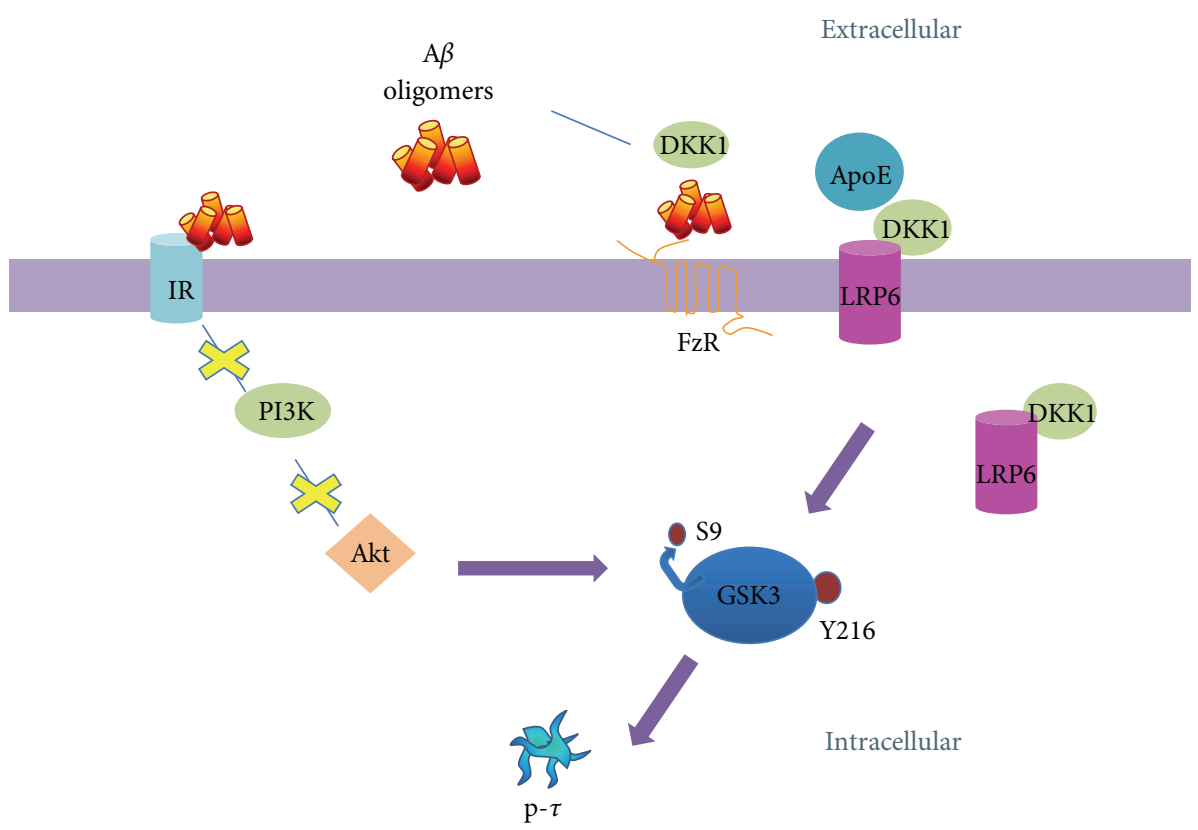

FIGURE 4: Proposed model of GSK3 activation by amyloid- $\beta$ protein in AD. Amyloid- $\beta$ oligomers bind to the insulin receptor and inhibit PI3K/Akt pathway, and Akt is unable to phosphorylate and inactivate GSK3. A $\beta$ also induces the expression of DKK1, which internalizes LRP6 receptor and inhibits Wnt signaling leading to GSK3 activation. A $\beta$ can bind to Frizzled receptor (FzR) and inactivate Wnt signaling as well. ApoE also inhibits this signaling pathway and activates GSK3. Tau hyperphosphorylation and NFT formation may result from GSK3 overactivation.

degenerating neurons of AD brains [150]. Moreover, using Wnt and PI3K signaling inhibitors, cultured cortical neurons have shown increased tau phosphorylation and morphological changes mediated by GSK3 $\beta$ [151]. Taken together, this evidence suggests an important role for GSK3 in AD and supports the notion that GSK3 could be the link between amyloid and tau pathology [46] (Figure 4).

\section{Concluding Remarks}

GSK3 has attracted a great deal of interest due to the myriad of processes it controls. GSK3 is implicated in many fundamental functions, ranging from bioenergetics to developmental and plasticity events, particularly in the brain. Altered GSK3 activity in the brain negatively influences neuronal structure, which in turn may affect maintenance of neuronal circuits that support cognitive function. The use of therapeutic drugs to control GSK3 activity has been hampered by the variety of substrates targeted by this enzyme and the long-term ramifications of its downstream signaling. Future studies could focus on identifying spatiotemporal expression patterns of specific GSK3 isoforms in the brain with the goal of developing specific inhibitors for clinical use in devastating neurological diseases, such as AD.

\section{Acknowledgments}

This work was supported by PAPIIT IN219509-3. P. SalcedoTello was supported by CONACYT 220709.

\section{References}

[1] V. Stambolic, L. Ruel, and J. R. Woodgett, "Lithium inhibits glycogen synthase kinase-3 activity and mimics wingless signalling in intact cells," Current Biology, vol. 6, no. 12, pp. 1664-1668, 1996.

[2] S. Frame and P. Cohen, "GSK3 takes centre stage more than 20 years after its discovery," Biochemical Journal, vol. 359, no. 1, pp. 1-16, 2001.

[3] N. Embi, D. B. Rylatt, and P. Cohen, "Glycogen synthase kinase-3 from rabbit skeletal muscle. Separation from cyclicAMP-dependent protein kinase and phosphorylase kinase," European Journal of Biochemistry, vol. 107, no. 2, pp. 519527, 1980.

[4] J. R. Woodgett, "Molecular cloning and expression of glycogen synthase kinase-3/Factor A," EMBO Journal, vol. 9, no. 8, pp. 2431-2438, 1990.

[5] S. E. Plyte, K. Hughes, E. Nikolakaki, B. J. Pulverer, and J. R. Woodgett, "Glycogen synthase kinase-3: functions in oncogenesis and development," Biochimica et Biophysica Acta, vol. 1114, no. 2-3, pp. 147-162, 1992.

[6] F. Mukai, K. Ishiguro, Y. Sano, and S. C. Fujita, "Aternative splicing isoform of tau protein kinase I/glycogen synthase kinase $3 \beta$," Journal of Neurochemistry, vol. 81, no. 5, pp. 10731083, 2002.

[7] A. Ali, K. P. Hoeflich, and J. R. Woodgett, "Glycogen synthase kinase-3: properties, functions, and regulation," Chemical Reviews, vol. 101, no. 8, pp. 2527-2540, 2001.

[8] P. Cohen and S. Frame, "The renaissance of GSK3," Nature Reviews Molecular Cell Biology, vol. 2, no. 10, pp. 769-776, 2001. 
[9] J. R. Woodgett, "Judging a protein by more than its name: GSK-3," Science"s STKE, vol. 2001, no. 100, p. RE12, 2001.

[10] P. Cohen and M. Goedert, "GSK3 inhibitors: development and therapeutic potential," Nature Reviews Drug Discovery, vol. 3, no. 6, pp. 479-487, 2004.

[11] K. Hughes, E. Nikolakaki, S. E. Plyte, N. F. Totty, and J. R. Woodgett, "Modulation of the glycogen synthase kinase-3 family by tyrosine phosphorylation," EMBO Journal, vol. 12, no. 2, pp. 803-808, 1993.

[12] Q. M. Wang, C. J. Fiol, A. A. DePaoli-Roach, and P. J. Roach, "Glycogen synthase kinase- $3 \beta$ is a dual specificity kinase differentially regulated by tyrosine and serine/threonine phosphorylation," Journal of Biological Chemistry, vol. 269, no. 20, pp. 14566-14574, 1994.

[13] P. A. Lochhead, R. Kinstrie, G. Sibbet, T. Rawjee, N. Morrice, and V. Cleghone, "A chaperone-dependent GSK3 $\beta$ transitional intermediate mediates activation-loop autophosphorylation," Molecular Cell, vol. 24, no. 4, pp. 627-633, 2006.

[14] J. A. Hartigan, W. C. Xiong, and G. V. W. Johnson, "Glycogen synthase kinase $3 \beta$ is tyrosine phosphorylated by PYK2," Biochemical and Biophysical Research Communications, vol. 284, no. 2, pp. 485-489, 2001.

[15] A. Cole, S. Frame, and P. Cohen, "Further evidence that the tyrosine phosphorylation of glycogen synthase kinase3 (GSK3) in mammalian cells is an autophosphorylation event," Biochemical Journal, vol. 377, no. 1, pp. 249-255, 2004.

[16] R. S. Jope and G. V. W. Johnson, "The glamour and gloom of glycogen synthase kinase-3," Trends in Biochemical Sciences, vol. 29, no. 2, pp. 95-102, 2004.

[17] T. M. Thornton, G. Pedraza-Alva, B. Deng et al., "Phosphorylation by $\mathrm{p} 38$ MAPK as an alternative pathway for GSK3 $\beta$ inactivation," Science, vol. 320, no. 5876, pp. 667-670, 2008.

[18] K. M. Cadigan and Y. I. Liu, "Wnt signaling: complexity at the surface," Journal of Cell Science, vol. 119, no. 3, pp. 395402, 2006.

[19] P. Goñi-Oliver, J. J. Lucas, J. Avila, and F. Hernández, "Nterminal cleavage of GSK-3 by calpain: a new form of GSK-3 regulation," Journal of Biological Chemistry, vol. 282, no. 31, pp. 22406-22413, 2007.

[20] G. N. Bijur and R. S. Jope, "Glycogen synthase kinase-3 beta is highly activated in nuclei and mitochondria," Neuroreport, vol. 14, no. 18, pp. 2415-2419, 2003.

[21] P. H. Sugden, S. J. Fuller, S. C. Weiss, and A. Clerk, "Glycogen synthase kinase 3 (GSK3) in the heart: a point of integration in hypertrophic signalling and a therapeutic target? A critical analysis," British Journal of Pharmacology, vol. 153, no. 1, pp. S137-S153, 2008.

[22] F. Hernández, E. G. de Barreda, A. Fuster-Matanzo, P. GoñiOliver, J. J. Lucas, and J. Avila, "The role of GSK3 in Alzheimer disease," Brain Research Bulletin, vol. 80, no. 4-5, pp. 248-250, 2009.

[23] H. B. Yao, P. C. Shaw, C. C. Wong, and D. C. C. Wan, "Expression of glycogen synthase kinase-3 isoforms in mouse tissues and their transcription in the brain," Journal of Chemical Neuroanatomy, vol. 23, no. 4, pp. 291-297, 2002.

[24] K. P. Giese, "GSK-3: a key player in neurodegeneration and memory," IUBMB Life, vol. 61, no. 5, pp. 516-521, 2009.

[25] S. J. Lee, Y. H. Chung, K. M. Joo et al., "Age-related changes in glycogen synthase kinase $3 \beta$ (GSK $3 \beta)$ immunoreactivity in the central nervous system of rats," Neuroscience Letters, vol. 409, no. 2, pp. 134-139, 2006.
[26] M. Takahashi, K. Tomizawa, R. Kato et al., "Localization and developmental changes of $\tau$ protein kinase I/glycogen synthase kinase- $3 \beta$ in rat brain," Journal of Neurochemistry, vol. 63, no. 1, pp. 245-255, 1994.

[27] M. Takahashi, K. Tomizawa, and K. Ishiguro, "Distribution of tau protein kinase I/glycogen synthase kinase-3 $\beta$, phosphatases $2 \mathrm{~A}$ and $2 \mathrm{~B}$, and phosphorylated tau in the developing rat brain," Brain Research, vol. 857, no. 1-2, pp. 193-206, 2000.

[28] K. Leroy and J. P. Brion, "Developmental expression and localization of glycogen synthase kinase- $3 \beta$ in rat brain," Journal of Chemical Neuroanatomy, vol. 16, no. 4, pp. 279293, 1999.

[29] M. P.M. Soutar, W. -Y. Kim, R. Williamson et al., "Evidence that glycogen synthase kinase-3 isoforms have distinct substrate preference in the brain," Journal of Neurochemistry, vol. 115, no. 4, pp. 974-983, 2010.

[30] R. G. Goold and P. R. Gordon-Weeks, "Glycogen synthase kinase $3 \beta$ and the regulation of axon growth," Biochemical Society Transactions, vol. 32, no. 5, pp. 809-811, 2004.

[31] N. Trivedi, P. Marsh, R. G. Goold, A. Wood-Kaczmar, and P. R. Gordon-Weeks, "Glycogen synthase kinase-3 $\beta$ phosphorylation of MAP1B at Ser1260 and Thr1265 is spatially restricted to growing axons," Journal of Cell Science, vol. 118, no. 5, pp. 993-1005, 2005.

[32] Z. Castaño, P. R. Gordon-Weeks, and R. M. Kypta, "The neuron-specific isoform of glycogen synthase kinase- $3 \beta$ is required for axon growth," Journal of Neurochemistry, vol. 113, no. 1, pp. 117-130, 2010.

[33] W. T. O’Brien, A. D. Harper, F. Jové et al., "Glycogen synthase kinase- $3 \beta$ haploinsufficiency mimics the behavioral and molecular effects of lithium," Journal of Neuroscience, vol. 24, no. 30, pp. 6791-6798, 2004.

[34] J. M. Beaulieu, X. Zhang, R. M. Rodriguiz et al., "Role of GSK $3 \beta$ in behavioral abnormalities induced by serotonin deficiency," Proceedings of the National Academy of Sciences of the United States of America, vol. 105, no. 4, pp. 1333-1338, 2008.

[35] T. Kimura, S. Yamashita, S. Nakao et al., "GSK-3 $\beta$ is required for memory reconsolidation in adult brain," PLoS One, vol. 3, no. 10, Article ID e3540, 2008.

[36] K. MacAulay, B. W. Doble, S. Patel et al., "Glycogen synthase kinase $3 \alpha$-specific regulation of murine hepatic glycogen metabolism," Cell Metabolism, vol. 6, no. 4, pp. 329-337, 2007.

[37] O. Kaidanovich-Beilin, T. V. Lipina, K. Takao et al., "Abnormalities in brain structure and behavior in GSK-3alpha mutant mice," Molecular Brain, vol. 2, no. 1, article no. 35, 2009.

[38] J. Prickaerts, D. Moechars, K. Cryns et al., "Transgenic mice overexpressing glycogen synthase kinase $3 \beta$ : a putative model of hyperactivity and mania," Journal of Neuroscience, vol. 26, no. 35, pp. 9022-9029, 2006.

[39] E. G. de Barreda, M. Pérez, P. Gómez-Ramos et al., "Tauknockout mice show reduced GSK3-induced hippocampal degeneration and learning deficits," Neurobiology of Disease, vol. 37, no. 3, pp. 622-629, 2010.

[40] F. Q. Zhou and W. D. Snider, "GSK-3 $\beta$ and microtubule assembly in axons," Science, vol. 308, no. 5719, pp. 211-214, 2005.

[41] J. M. Beaulieu, R. R. Gainetdinov, and M. G. Caron, "Akt/GSK3 signaling in the action of psychotropic drugs," Annual Review of Pharmacology and Toxicology, vol. 49, pp. 327-347, 2009. 
[42] R. S. Jope and M. S. Roh, "Glycogen synthase kinase-3 (GSK3) in psychiatric disease and therapeutic interventions," Current Drug Targets, vol. 7, no. 11, pp. 1421-1434, 2006.

[43] M. P. Mazanetz and P. M. Fischer, "Untangling tau hyperphosphorylation in drug design for neurodegenerative diseases," Nature Reviews Drug Discovery, vol. 6, no. 6, pp. 464479, 2007.

[44] S. Lovestone, R. Killick, M. Di Forti, and R. Murray, "Schizophrenia as a GSK-3 dysregulation disorder," Trends in Neurosciences, vol. 30, no. 4, pp. 142-149, 2007.

[45] G. V. Rayasam, V. K. Tulasi, R. Sodhi, J. A. Davis, and A. Ray, "Glycogen synthase kinase 3: more than a namesake," British Journal of Pharmacology, vol. 156, no. 6, pp. 885-898, 2009.

[46] F. Hernández, E. Gómez de Barreda, A. Fuster-Matanzo, J. J. Lucas, and J. Avila, "GSK3: a possible link between beta amyloid peptide and tau protein," Experimental Neurology, vol. 223, no. 2, pp. 322-325, 2010.

[47] J. Avila, F. Wandosell, and F. Hernández, "Role of glycogen synthase kinase-3 in Alzheimer's disease pathogenesis and glycogen synthase kinase-3 inhibitors," Expert Review of Neurotherapeutics, vol. 10, no. 5, pp. 703-710, 2010.

[48] E. E. Rodgers and A. B. Theibert, "Functions of PI 3-kinase in development of the nervous system," International Journal of Developmental Neuroscience, vol. 20, no. 3-5, pp. 187-197, 2002.

[49] E. Castellano and J. Downward, "Role of RAS in the regulation of PI 3-kinase," Current Topics in Microbiology and Immunology, vol. 346, pp. 143-169, 2010.

[50] J. Chen, S. P. Chang, and S. J. Tang, "Activity-dependent synaptic Wnt release regulates hippocampal long term potentiation," Journal of Biological Chemistry, vol. 281, no. 17, pp. 11910-11916, 2006.

[51] S. D. Speese and V. Budnik, "Wnts: up-and-coming at the synapse," Trends in Neurosciences, vol. 30, no. 6, pp. 268-275, 2007.

[52] G. G. Farías, J. A. Godoy, W. Cerpa, L. Varela-Nallar, and N. C. Inestrosa, "Wnt signaling modulates pre- and postsynaptic maturation: therapeutic considerations," Developmental Dynamics, vol. 239, no. 1, pp. 94-101, 2010.

[53] E.-M. Hur and F.-Q. Zhou, "GSK3 signalling in neural development," Nature Reviews Neuroscience, vol. 11, no. 8, pp. 539-551, 2010.

[54] G. V. De Ferrari and and N. C. Inestrosa, "Wnt signaling function in Alzheimer's disease," Brain Research Reviews, vol. 33, no. 1, pp. 1-12, 2000.

[55] M. Wehrli, S. T. Dougan, K. Caldwell et al., "Arrow encodes an LDL-receptor-related protein essential for Wingless signalling," Nature, vol. 407, no. 6803, pp. 527-530, 2000.

[56] S. Ikeda, S. Kishida, H. Yamamoto, H. Murai, S. Koyama, and A. Kikuchi, "Axin, a negative regulator of the Wnt signaling pathway, forms a complex with GSK-3 $\beta$ and $\beta$ catenin and promotes GSK- $3 \beta$-dependent phosphorylation of $\beta$-catenin," EMBO Journal, vol. 17, no. 5, pp. 1371-1384, 1998.

[57] M. Van Noort and H. Clevers, "TCF transcription factors, mediators of Wnt-signaling in development and cancer," Developmental Biology, vol. 244, no. 1, pp. 1-8, 2002.

[58] V. F. Taelman, R. Dobrowolski, J. -L. Plouhinec et al., "Wnt signaling requires sequestration of Glycogen Synthase Kinase 3 inside multivesicular endosomes," Cell, vol. 143, no. 7, pp. 1136-1148, 2010.

[59] Y. Kawano and R. Kypta, "Secreted antagonists of the Wnt signalling pathway," Journal of Cell Science, vol. 116, no. 13, pp. 2627-2634, 2003.
[60] Y. Mao, X. Ge, C. L. Frank et al., "Disrupted in schizophrenia 1 regulates neuronal progenitor proliferation via modulation of GSK $3 \beta / \beta$-catenin signaling," Cell, vol. 136, no. 6, pp. 10171031, 2009.

[61] J. M. Beaulieu, T. D. Sotnikova, S. Marion, R. J. Lefkowitz, R. R. Gainetdinov, and M. G. Caron, "An Akt/ $\beta$-arrestin 2/PP2A signaling complex mediates dopaminergic neurotransmission and behavior," Cell, vol. 122, no. 2, pp. 261-273, 2005.

[62] L. Mei and W. C. Xiong, "Neuregulin 1 in neural development, synaptic plasticity and schizophrenia," Nature Reviews Neuroscience, vol. 9, no. 6, pp. 437-452, 2008.

[63] G. Mckenzie, G. Ward, Y. Stallwood et al., "Cellular notch responsiveness is defined by phosphoinositide 3-kinasedependent-signals," BMC Cell Biology, vol. 7, article no. 10, 2006.

[64] Y. Wang, S. L. Chan, L. Miele et al., "Involvement of Notch signaling in hippocampal synaptic plasticity," Proceedings of the National Academy of Sciences of the United States of America, vol. 101, no. 25, pp. 9458-9462, 2004.

[65] P. R. Gordon-Weeks, "Microtubules and growth cone function," Journal of Neurobiology, vol. 58, no. 1, pp. 70-83, 2004.

[66] F. R. Lucas, R. G. Goold, P. R. Gordon-Weeks, and P. C. Salinas, "Inhibition of GSK- $3 \beta$ leading to the loss of phosphorylated MAP-1B is an early event in axonal remodelling induced by WNT-7a or lithium," Journal of Cell Science, vol. 111, no. 10, pp. 1351-1361, 1998.

[67] R. G. Goold, R. Owen, and P. R. Gordon-Weeks, "Glycogen synthase kinase $3 \beta$ phosphorylation of microtubuleassociated protein $1 \mathrm{~B}$ regulates the stability of microtubules in growth cones," Journal of Cell Science, vol. 112, no. 19, pp. 3373-3384, 1999.

[68] R. G. Goold and P. R. Gordon-Weeks, "The MAP kinase pathway is upstream of the activation of GSK3 $\beta$ that enables it to phosphorylate MAP1B and contributes to the stimulation of axon growth," Molecular and Cellular Neuroscience, vol. 28, no. 3, pp. 524-534, 2005.

[69] C. González-Billault, J. A. Del Río, J. M. Ureña et al., "A role of MAP1B in reelin-dependent neuronal migration," Cerebral Cortex, vol. 15, no. 8, pp. 1134-1145, 2005.

[70] W. Y. Kim, F. Q. Zhou, J. Zhou et al., "Essential roles for GSK$3 \mathrm{~s}$ and GSK-3-primed substrates in neurotrophin-induced and hippocampal axon growth," Neuron, vol. 52, no. 6, pp. 981-996, 2006.

[71] C. Conde and A. Cáceres, "Microtubule assembly, organization and dynamics in axons and dendrites," Nature Reviews Neuroscience, vol. 10, no. 5, pp. 319-332, 2009.

[72] S. Geraldo and P. R. Gordon-Weeks, "Cytoskeletal dynamics in growth-cone steering," Journal of Cell Science, vol. 122, no. 20, pp. 3595-3604, 2009.

[73] B. J. Eickholt, F. S. Walsh, and P. Doherty, "An inactive pool of GSK-3 at the leading edge of growth cones is implicated in Semaphorin 3A signaling," Journal of Cell Biology, vol. 157, no. 2, pp. 211-217, 2002.

[74] S. H. Shi, T. Cheng, L. Y. Jan, and Y. N. Jan, "APC and GSK$3 \beta$ are involved in mPar3 targeting to the nascent axon and establishment of neuronal polarity," Current Biology, vol. 14, no. 22, pp. 2025-2032, 2004.

[75] H. Jiang, W. Guo, X. Liang, and YI. Rao, "Both the establishment and the maintenance of neuronal polarity require active mechanisms: critical roles of GSK-3 $\beta$ and its upstream regulators," Cell, vol. 120, no. 1, pp. 123-135, 2005. 
[76] T. Yoshimura, Y. Kawano, N. Arimura, S. Kawabata, A. Kikuchi, and K. Kaibuchi, "GSK-3 $\beta$ regulates phosphorylation of CRMP-2 and neuronal polarity," Cell, vol. 120, no. 1, pp. 137-149, 2005.

[77] O. Krylova, J. Herreros, K. E. Cleverley et al., "WNT-3, expressed by motoneurons, regulates terminal arborization of neurotrophin-3-responsive spinal sensory neurons," Neuron, vol. 35, no. 6, pp. 1043-1056, 2002.

[78] A. I. Lyuksyutova, C. C. Lu, N. Milanesio et al., "Anteriorposterior guidance of commissural axons by Wnt-frizzled signaling," Science, vol. 302, no. 5652, pp. 1984-1988, 2003.

[79] R. Owen and P. R. Gordon-Weeks, "Inhibition of glycogen synthase kinase $3 \beta$ in sensory neurons in culture alters filopodia dynamics and microtubule distribution in growth cones," Molecular and Cellular Neuroscience, vol. 23, no. 4, pp. 626-637, 2003.

[80] O. Krylova, M. J. Messenger, and P. C. Salinas, "Dishevelled-1 regulates microtubule stability: a new function mediated by glycogen synthase kinase-3 $\beta$," Journal of Cell Biology, vol. 151, no. 1, pp. 83-93, 2000.

[81] A. Ahmad-Annuar, L. Ciani, I. Simeonidis et al., "Signaling across the synapse: a role for Wnt and Dishevelled in presynaptic assembly and neurotransmitter release," Journal of Cell Biology, vol. 174, no. 1, pp. 127-139, 2006.

[82] Y. Endo and J. S. Rubin, "Wnt signaling and neurite outgrowth: insights and questions," Cancer Science, vol. 98, no. 9, pp. 1311-1317, 2007.

[83] C. Gao and Y. G. Chen, "Dishevelled: the hub of Wnt signaling.," Cellular Signalling, vol. 22, no. 5, pp. 717-727, 2010.

[84] P. C. Salinas, "Retrograde signalling at the synapse: a role for Wnt proteins," Biochemical Society Transactions, vol. 33, no. 6, pp. 1295-1298, 2005.

[85] P. C. Salinas, "Wnt factors in axonal remodelling and synaptogenesis," Biochemical Society Symposium, vol. 65, pp. 101-109, 1999.

[86] L. Ciani, O. Krylova, M. J. Smalley, T. C. Dale, and P. C. Salinas, "A divergent canonical WNT-signaling pathway regulates microtubule dynamics: dishevelled signals locally to stabilize microtubules," Journal of Cell Biology, vol. 164, no. 2, pp. 243-253, 2004.

[87] A. C. Hall, F. R. Lucas, and P. C. Salinas, "Axonal remodeling and synaptic differentiation in the cerebellum is regulated by WNT-7a signaling," Cell, vol. 100, no. 5, pp. 525-535, 2000.

[88] F. R. Lucas and P. C. Salinas, "WNT-7a induces axonal remodeling and increases synapsin I levels in cerebellar neurons," Developmental Biology, vol. 192, no. 1, pp. 31-44, 1997.

[89] L. S. Chin, L. Li, A. Ferreira, K. S. Kosik, and P. Greengard, "Impairment of axonal development and of synaptogenesis in hippocampal neurons of synapsin I-deficient mice," Proceedings of the National Academy of Sciences of the United States of America, vol. 92, no. 20, pp. 9230-9234, 1995.

[90] T. W. Rosahl, D. Spillane, M. Missler et al., "Essential functions of synapsins I and II in synaptic vesicle regulation," Nature, vol. 375, no. 6531, pp. 488-493, 1995.

[91] L.-Q. Zhu, S.-H. Wang, D. Liu et al., "Activation of glycogen synthase kinase-3 inhibits long-term potentiation with synapse-associated impairments," Journal of Neuroscience, vol. 27, no. 45, pp. 12211-12220, 2007.

[92] E. K. Davis, Y. Zou, and A. Ghosh, "Wnts acting through canonical and noncanonical signaling pathways exert opposite effects on hippocampal synapse formation," Neural Development, vol. 3, no. 1, article no. 32, 2008.
[93] F. Plattner, M. Angelo, and K. P. Giese, "The roles of cyclindependent kinase 5 and glycogen synthase kinase 3 in tau hyperphosphorylation," Journal of Biological Chemistry, vol. 281, no. 35, pp. 25457-25465, 2006.

[94] E. L. Clayton, N. Sue, K. J. Smillie et al., "Dynamin i phosphorylation by GSK3 controls activity-dependent bulk endocytosis of synaptic vesicles," Nature Neuroscience, vol. 13, no. 7, pp. 845-851, 2010.

[95] C. Pittenger and E. Kandel, "A genetic switch for long-term memory," Comptes Rendus de l'Academie des Sciences - Serie III, vol. 321, no. 2-3, pp. 91-96, 1998.

[96] E. P. Huang, "Synaptic plasticity: going through phases with LTP," Current Biology, vol. 8, no. 10, pp. R350-R352, 1998.

[97] P. K. Stanton, "LTD, LTP, and the sliding threshold for longterm synaptic plasticity," Hippocampus, vol. 6, no. 1, pp. 3542, 1996.

[98] J. Lisman, "Long-term potentiation: outstanding questions and attempted synthesis," Philosophical Transactions of the Royal Society B, vol. 358, no. 1432, pp. 829-842, 2003.

[99] R. C. Malenka and M. F. Bear, "LTP and LTD: an embarrassment of riches," Neuron, vol. 44, no. 1, pp. 5-21, 2004.

[100] C. Hooper, V. Markevich, F. Plattner et al., "Glycogen synthase kinase-3 inhibition is integral to long-term potentiation," European Journal of Neuroscience, vol. 25, no. 1, pp. 81-86, 2007.

[101] S. Peineau, C. Taghibiglou, C. Bradley et al., "LTP inhibits LTD in the hippocampus via regulation of GSK $3 \beta$," Neuron, vol. 53, no. 5, pp. 703-717, 2007.

[102] F. Cai, F. Wang, F. K. Lin et al., "Redox modulation of longterm potentiation in the hippocampus via regulation of the glycogen synthase kinase- $3 \beta$ pathway," Free Radical Biology and Medicine, vol. 45, no. 7, pp. 964-970, 2008.

[103] R. A. Nichols, T. J. Chilcote, A. J. Czernik, and P. Greengard, "Synapsin I regulates glutamate release from rat brain synaptosomes," Journal of Neurochemistry, vol. 58, no. 2, pp. 783-785, 1992.

[104] P. Greengard, F. Valtorta, A. J. Czernik, and F. Benfenati, "Synaptic vesicle phosphoproteins and regulation of synaptic function," Science, vol. 259, no. 5096, pp. 780-785, 1993.

[105] V. A. Pieribone, O. Shupliakov, L. Brodin, S. HilfikerRothenfluh, A. J. Czernik, and P. Greengard, "Distinct pools of synaptic vesicles in neurotransmitter release," Nature, vol. 375, no. 6531, pp. 493-497, 1995.

[106] S. Hilfiker, V. A. Pieribone, A. J. Czernik, H.-T. Kao, G. J. Augustine, and P. Greengard, "Synapsins as regulators of neurotransmitter release," Philosophical Transactions of the Royal Society B, vol. 354, no. 1381, pp. 269-279, 1999.

[107] P. Chi, P. Greengard, and T. A. Ryan, "Synapsin dispersion and reclustering during synaptic activity," Nature Neuroscience, vol. 4, no. 12, pp. 1187-1193, 2001.

[108] O. Bloom, E. Evergren, N. Tomilin et al., "Colocalization of synapsin and actin during synaptic vesicle recycling," Journal of Cell Biology, vol. 161, no. 4, pp. 737-747, 2003.

[109] R. H. Melloni Jr., L. M. Hemmendinger, J. E. Hamos, and L. J. DeGennaro, "Synapsin I gene expression in the adult rat brain with comparative analysis of mRNA and protein in the hippocampus," Journal of Comparative Neurology, vol. 327, no. 4, pp. 507-520, 1993.

[110] K. Sato, K. Morimoto, S. Suemaru, T. Sato, and N. Yamada, "Increased synapsin I immunoreactivity during long-term potentiation in rat hippocampus," Brain Research, vol. 872, no. 1-2, pp. 219-222, 2000. 
[111] Z. A. Bortolotto and G. L. Collingridge, "A role for protein kinase $\mathrm{C}$ in a form of metaplasticity that regulates the induction of long-term potentiation at CA1 synapses of the adult rat hippocampus," European Journal of Neuroscience, vol. 12, no. 11, pp. 4055-4062, 2000.

[112] P. P. Sanna, M. Cammalleri, F. Berton et al., "Phosphatidylinositol 3-kinase is required for the expression but not for the induction or the maintenance of longterm potentiation in the hippocampal CA1 region," Journal of Neuroscience, vol. 22, no. 9, pp. 3359-3365, 2002.

[113] P. Opazo, A. M. Watabe, S. G.N. Grant, and T. J. O’Dell, "Phosphatidylinositol 3-kinase regulates the induction of long-term potentiation through extracellular signal-related kinase-independent mechanisms," Journal of Neuroscience, vol. 23, no. 9, pp. 3679-3688, 2003.

[114] F. Gardoni, A. Caputi, M. Cimino, L. Pastorino, F. Cattabeni, and M. Di Luca, "Calcium/calmodulin-dependent protein kinase II is associated with NR2A/B subunits of NMDA receptor in postsynaptic densities," Journal of Neurochemistry, vol. 71, no. 4, pp. 1733-1741, 1998.

[115] B. Teter and J. W. Ashford, "Neuroplasticity in Alzheimer's disease," Journal of Neuroscience Research, vol. 70, no. 3, pp. 402-437, 2002.

[116] E. C. Beattie, R. C. Carroll, X. Yu et al., "Regulation of AMPA receptor endocytosis by a signaling mechanism shared with LTD," Nature Neuroscience, vol. 3, no. 12, pp. 1291-1300, 2000.

[117] G. L. Collingridge, J. T. R. Isaac, and T. W. Yu, "Receptor trafficking and synaptic plasticity," Nature Reviews Neuroscience, vol. 5, no. 12, pp. 952-962, 2004.

[118] J. Lisman, "A mechanism for the Hebb and the anti-Hebb processes underlying learning and memory," Proceedings of the National Academy of Sciences of the United States of America, vol. 86, no. 23, pp. 9574-9578, 1989.

[119] S. A. Purro, L. Ciani, M. Hoyos-Flight, E. Stamatakou, E. Siomou, and P. C. Salinas, "Wnt regulates axon behavior through changes in microtubule growth directionality: a new role for adenomatous polyposis coli," Journal of Neuroscience, vol. 28, no. 34, pp. 8644-8654, 2008.

[120] F. Hernández, J. Borrell, C. Guaza, J. Avila, and J. J. Lucas, "Spatial learning deficit in transgenic mice that conditionally over-express GSK-3 $\beta$ in the brain but do not form tau filaments," Journal of Neurochemistry, vol. 83, no. 6, pp. 15291533, 2002.

[121] S. Peineau, C. Bradley, C. Taghibiglou et al., "The role of GSK-3 in synaptic plasticity," British Journal of Pharmacology, vol. 153, supplement 1, pp. S428-S437, 2008.

[122] C. Hooper, R. Killick, and S. Lovestone, "The GSK3 hypothesis of Alzheimer's disease," Journal of Neurochemistry, vol. 104, no. 6, pp. 1433-1439, 2008.

[123] A. Diaz, L. Mendieta, E. Zenteno, J. Guevara, and I. D. Limon, "The role of NOS in the impairment of spatial memory and damaged neurons in rats injected with amyloid beta 25-35 into the temporal cortex," Pharmacology Biochemistry and Behavior, vol. 98, no. 1, pp. 67-75, 2011.

[124] A. Sydow, A. Van Der Jeugd, F. Zheng et al., "Tau-induced defects in synaptic plasticity, learning, and memory are reversible in transgenic mice after switching off the toxic tau mutant," Journal of Neuroscience, vol. 31, no. 7, pp. 25112525, 2011.

[125] X. Sun, S. Sato, O. Murayama et al., "Lithium inhibits amyloid secretion in COS7 cells transfected with amyloid precursor protein C100," Neuroscience Letters, vol. 321, no. 1-2, pp. 61-64, 2002.
[126] C. J. Phiel, C. A. Wilson, V. M. Y. Lee, and P. S. Klein, "GSK$3 \alpha$ regulates production of Alzheimer's disease amyloid- $\beta$ peptides," Nature, vol. 423, no. 6938, pp. 435-439, 2003.

[127] K. Iqbal and I. Grundke-Iqbal, "Discoveries of Tau, abnormally hyperphosphorylated tau and others of neurofibrillary degeneration: a personal historical perspective," Journal of Alzheimer's Disease, vol. 9, no. 3, pp. 219-242, 2006.

[128] K. Ishiguro, A. Shiratsuchi, S. Sato et al., "Glycogen synthase kinase $3 \beta$ is identical to tau protein kinase I generating several epitopes of paired helical filaments," FEBS Letters, vol. 325, no. 3, pp. 167-172, 1993.

[129] J. J. Pei, T. Tanaka, Y. C. Tung, E. Braak, K. Iqbal, and I. Grundke-Iqbal, "Distribution, levels, and activity of glycogen synthase kinase-3 in the Alzheimer disease brain," Journal of Neuropathology and Experimental Neurology, vol. 56, no. 1, pp. 70-78, 1997.

[130] D. P. Hanger, B. H. Anderton, and W. Noble, "Tau phosphorylation: the therapeutic challenge for neurodegenerative disease," Trends in Molecular Medicine, vol. 15, no. 3, pp. 112119, 2009.

[131] A. Leroy, I. Landrieu, and I. Huvent, "Spectroscopic studies of GSK3 $\beta$ phosphorylation of the neuronal Tau protein and its interaction with the $\mathrm{N}$-terminal domain of apolipoprotein E," Journal of Biological Chemistry, vol. 285, no. 43, pp. 33435-33444, 2010.

[132] J. J. Lucas, F. Hernández, P. Gómez-Ramos, M. A. Morán, R. Hen, and J. Avila, "Decreased nuclear $\beta$-catenin, tau hyperphosphorylation and neurodegeneration in GSK-3 $\beta$ conditional transgenic mice," EMBO Journal, vol. 20, no. 1-2, pp. 27-39, 2001.

[133] T. Engel, P. Goñi-Oliver, J. J. Lucas, J. Avila, and F. Hernández, "Chronic lithium administration to FTDP-17 tau and GSK$3 \beta$ overexpressing mice prevents tau hyperphosphorylation and neurofibrillary tangle formation, but pre-formed neurofibrillary tangles do not revert," Journal of Neurochemistry, vol. 99, no. 6, pp. 1445-1455, 2006.

[134] G. R. Jackson, M. Wiedau-Pazos, T. K. Sang et al., "Human wild-type tau interacts with wingless pathway components and produces neurofibrillary pathology in Drosophila," Neuron, vol. 34, no. 4, pp. 509-519, 2002.

[135] M. Pérez, F. Hernández, F. Lim, J. Díaz-Nido, and J. Avila, "Chronic lithium treatment decreases mutant tau protein aggregation in a transgenic mouse model," Journal of Alzheimer's Disease, vol. 5, no. 4, pp. 301-308, 2003.

[136] W. Noble, E. Planel, C. Zehr et al., "Inhibition of glycogen synthase kinase- 3 by lithium correlates with reduced tauopathy and degeneration in vivo," Proceedings of the National Academy of Sciences of the United States of America, vol. 102, no. 19, pp. 6990-6995, 2005.

[137] L. Serenó, M. Coma, M. Rodríguez et al., "A novel GSK$3 \beta$ inhibitor reduces Alzheimer's pathology and rescues neuronal loss in vivo," Neurobiology of Disease, vol. 35, no. 3, pp. 359-367, 2009.

[138] H. Yamaguchi, K. Ishiguro, T. Uchida, A. Takashima, C. A. Lemere, and K. Imahori, "Preferential labeling of Alzheimer neurofibrillary tangles with antisera for tau protein kinase (TPK) I/glycogen synthase kinase- $3 \beta$ and cyclin-dependent kinase 5, a component of TPK II," Acta Neuropathologica, vol. 92, no. 3, pp. 232-241, 1996.

[139] J. J. Pei, E. Braak, H. Braak et al., "Distribution of active glycogen synthase kinase $3 \beta$ (GSK-3 $\beta)$ in brains staged for Alzheimer disease neurofibrillary changes," Journal of Neuropathology and Experimental Neurology, vol. 58, no. 9, pp. 1010-1019, 1999. 
[140] I. Mateo, J. Infante, J. Llorca, E. Rodríguez, J. Berciano, and O. Combarros, "Association between glycogen synthase kinase- $3 \beta$ genetic polymorphism and late-onset Alzheimer's disease," Dementia and Geriatric Cognitive Disorders, vol. 21, no. 4, pp. 228-232, 2006.

[141] B. A. J. Schaffer, L. Bertram, B. L. Miller et al., "Association of GSK3B with Alzheimer disease and frontotemporal dementia," Archives of Neurology, vol. 65, no. 10, pp. 1368-1374, 2008.

[142] Y. Su, J. Ryder, B. Li et al., "Lithium, a common drug for bipolar disorder treatment, regulates amyloid- $\beta$ precursor protein processing," Biochemistry, vol. 43, no. 22, pp. 68996908, 2004.

[143] A. Takashima, K. Noguchi, G. Michel et al., "Exposure of rat hippocampal neurons to amyloid $\beta$ peptide $(25-35)$ induces the inactivation of phosphatidyl inositol-3 kinase and the activation of tau protein kinase I/glycogen synthase kinase3ß," Neuroscience Letters, vol. 203, no. 1, pp. 33-36, 1996.

[144] M. Townsend, T. Mehta, and D. J. Selkoe, "Soluble A $\beta$ inhibits specific signal transduction cascades common to the insulin receptor pathway," Journal of Biological Chemistry, vol. 282, no. 46, pp. 33305-33312, 2007.

[145] M. H. Magdesian, M. M. V. F. Carvalho, F. A. Mendes et al., "Amyloid- $\beta$ binds to the extracellular cysteine-rich domain of frizzled and inhibits Wnt/ $\beta$-catenin signaling," Journal of Biological Chemistry, vol. 283, no. 14, pp. 9359-9368, 2008.

[146] G. V. De Ferrari, A. Papassotiropoulos, T. Biechele et al., "Common genetic variation within the low-density lipoprotein receptor-related protein 6 and late-onset Alzheimer's disease," Proceedings of the National Academy of Sciences of the United States of America, vol. 104, no. 22, pp. 9434-9439, 2007.

[147] A. Caruso, M. Motolese, L. Iacovelli et al., "Inhibition of the canonical Wnt signaling pathway by apolipoprotein E4 in PC12 cells," Journal of Neurochemistry, vol. 98, no. 2, pp. 364371, 2006.

[148] W. J. Strittmatter, A. M. Saunders, D. Schmechel et al., "Apolipoprotein E: high-avidity binding to $\beta$-amyloid and increased frequency of type 4 allele in late-onset familial Alzheimer disease," Proceedings of the National Academy of Sciences of the United States of America, vol. 90, no. 5, pp. 1977-1981, 1993.

[149] A. Cedazo-Mínguez, B. O. Popescu, J. M. Blanco-Millán et al., "Apolipoprotein E and $\beta$-amyloid (1-42) regulation of glycogen synthase kinase- $3 \beta$," Journal of Neurochemistry, vol. 87, no. 5, pp. 1152-1164, 2003.

[150] A. Caricasole, A. Copani, F. Caraci et al., "Induction of Dickkopf-1, a negative modulator of the Wnt pathway, is associated with neuronal degeneration in Alzheimer's brain," Journal of Neuroscience, vol. 24, no. 26, pp. 6021-6027, 2004.

[151] O. Mercado-Gómez, K. Hernández-Fonseca, A. Villavicencio-Queijeiro, L. Massieu, J. Chimal-Monroy, and C. Arias, "Inhibition of Wnt and PI3K signaling modulates GSK- $3 \beta$ activity and induces morphological changes in cortical neurons: role of tau phosphorylation," Neurochemical Research, vol. 33, no. 8, pp. 1599-1609, 2008. 


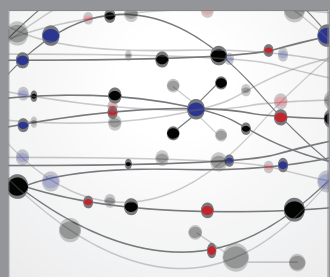

The Scientific World Journal
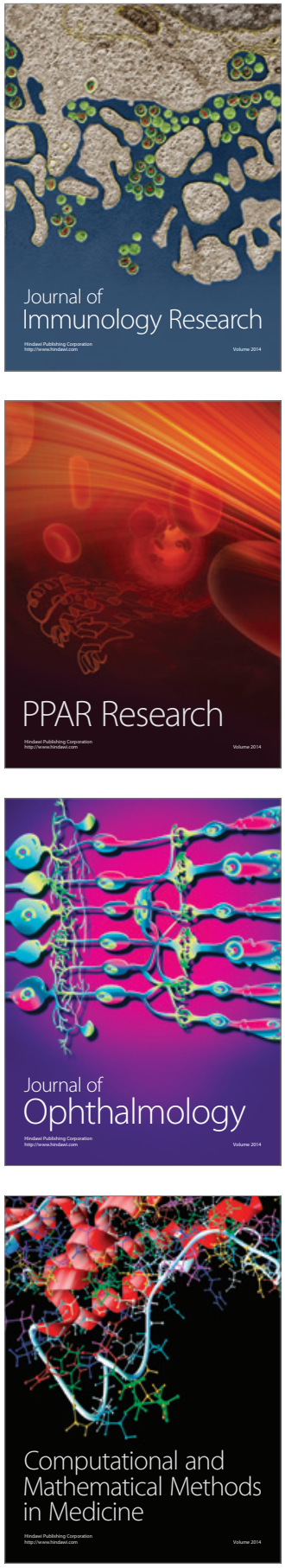

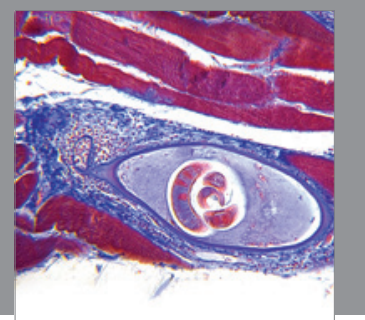

Gastroenterology

Research and Practice
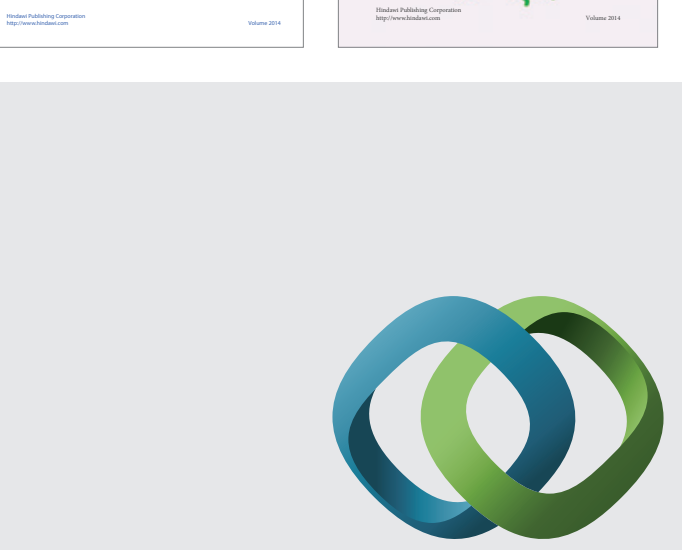

\section{Hindawi}

Submit your manuscripts at

http://www.hindawi.com
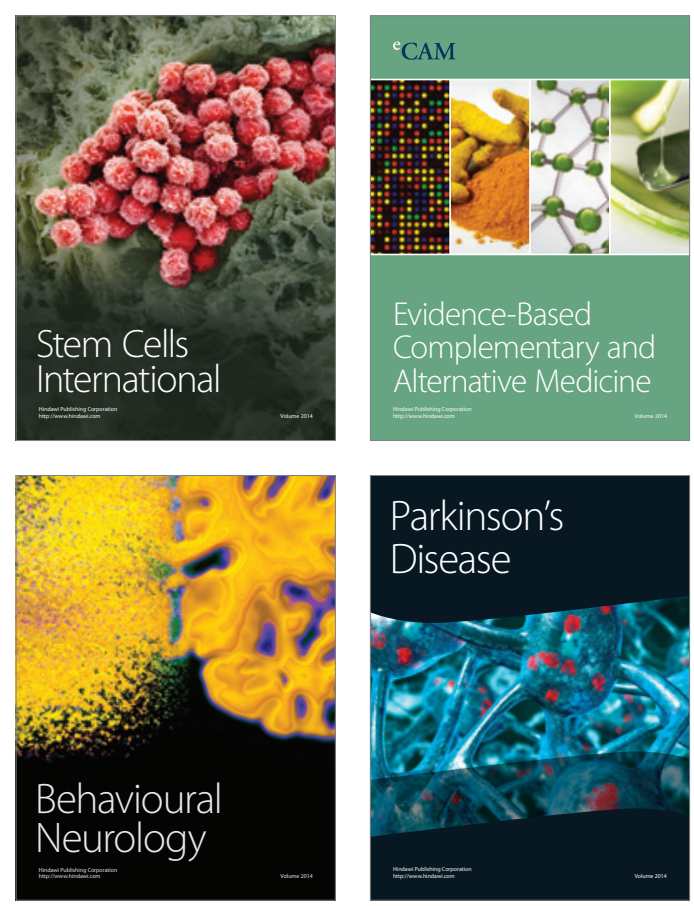

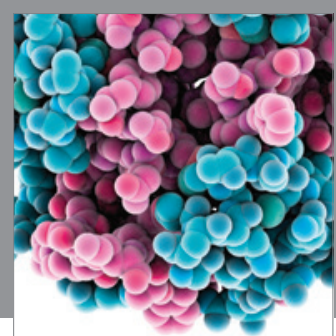

Journal of
Diabetes Research

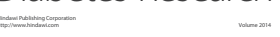

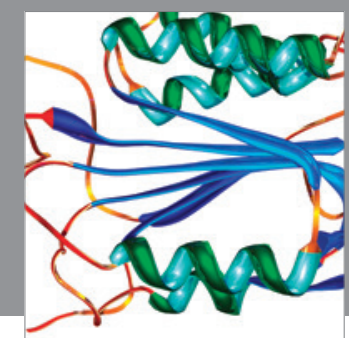

Disease Markers
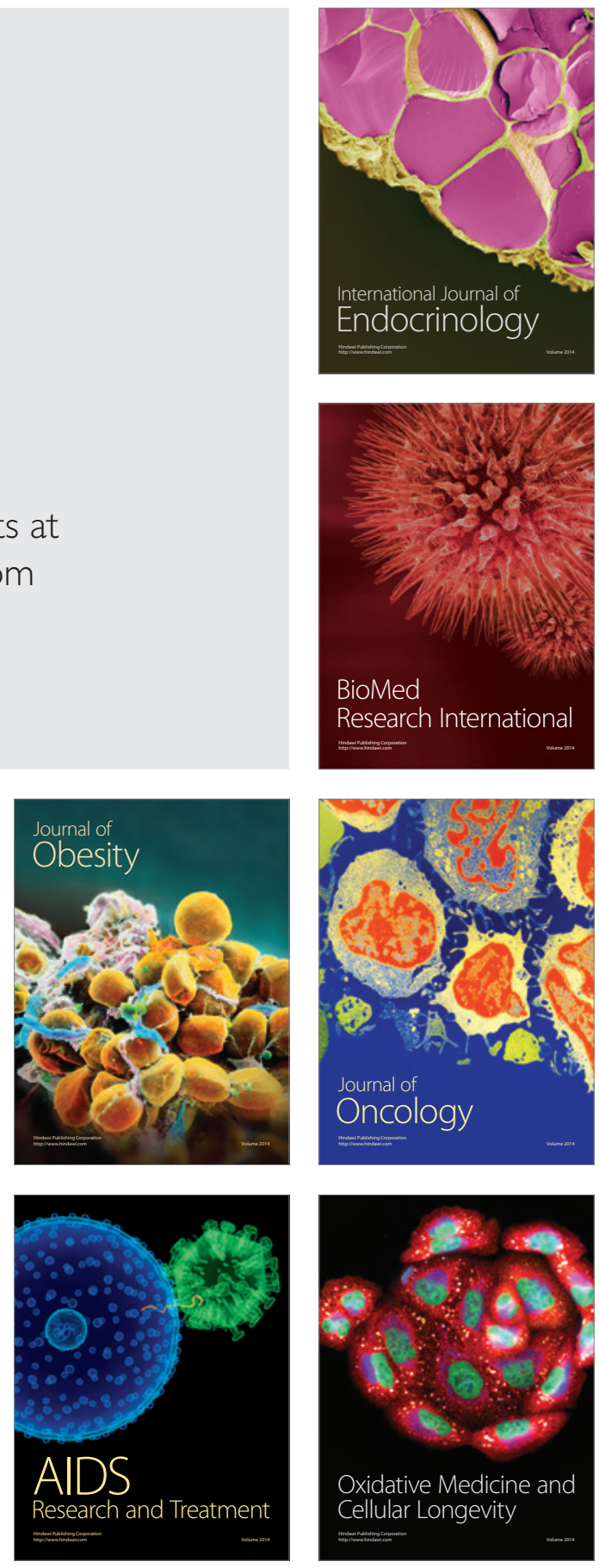